\title{
Applied Positive Psychology and Mindfulness: An Intervention Study
}

\author{
Jeannett Søndergaard Hansen ${ }^{*}\left(\mathbb{D}\right.$, Julie Søndergaard Povlsen ${ }^{2 *}\left(\mathbb{0}\right.$, , Hanne Irene Jensen $^{1,3^{*}}$ (i) \\ ${ }^{1}$ Department of Anesthesiology and Intensive Care, Lillebaelt Hospital Kolding, University Hospital of Southern Denmark, \\ Sygehusvej, Kolding, Denmark \\ ${ }^{2}$ Novavi Foundation, Soebysoegaard Prison and Halfway House Kvaerndrup, The Danish Prison and Probation Services, \\ Kværndrup, Denmark \\ ${ }^{3}$ Department of Regional Health Research, University of Southern Denmark, Odense, Denmark \\ Email: ${ }^{\star}$ Jeannett.soendergaard.hansen@rsyd.dk, *Juliepovlsen@gmail.com, ${ }^{\star}$ Hanne.irene.jensen@rsyd.dk
}

How to cite this paper: Hansen, J. S. Povlsen, J. S., \& Jensen, H. I. (2021). Applied Positive Psychology and Mindfulness: An Intervention Study. Psychology, $12,925-942$.

https://doi.org/10.4236/psych.2021.126056

Received: May 20, 2021

Accepted: June 22, 2021

Published: June 25, 2021

Copyright $\odot 2021$ by author(s) and Scientific Research Publishing Inc. This work is licensed under the Creative Commons Attribution International License (CC BY 4.0).

http://creativecommons.org/licenses/by/4.0/

\begin{abstract}
Healthcare professionals face numerous challenges in their daily work with core areas of treatment and care, but also in relation to organizational changes, changes in work assignments, and education. These challenges entail a need for mental robustness to prevent strain symptoms and stress. The aim of this study was to examine if the mental health and well-being of healthcare professionals can be improved via the teaching of and training in positive psychology and mindfulness. An intervention study was conducted with a fourday course with training in applied and theoretical aspects of positive psychology and mindfulness. The 23 participants were nurses and secretaries employed at a regional hospital in Denmark. The effects of the intervention were assessed by semi-structured interviews and quantitative measurements of well-being, positivity, and self-compassion. The participants described that they had learned techniques to face problems and challenges in a new way. The main themes from the qualitative analysis were increased positivity and strengths/skills, better mental gearshift, serenity, and increased self-compassion. Quantitative results showed an increase in the positivity-test, self-compassion test, and WHO-5 scale during the training period and a fade in the results 3-months post-intervention. Further research is necessary to confirm a significant increase in robustness and reduction in strain symptoms. Applying positive psychology and mindfulness may increase the positivity and mental robustness among healthcare professionals, and this study has described a model to teach knowledge and train practice skills from theories related to positive psychology and mindfulness.
\end{abstract}

\section{Keywords}

Positive Psychology, Mindfulness, Meditation, Resilience, 
Healthcare Professionals

\section{Introduction}

Healthcare professionals face numerous challenges in their daily work. This may be in relation to core areas of treatment and care, but also in relation to organizational changes, changes in work assignments, and education. These challenges entail a need for a certain degree of mental robustness to prevent strain symptoms and stress (McAlister \& Lowe, 2011). Contemporary healthcare is both challenging and complex (Riet et al., 2018). Therefore, it is important that healthcare professionals develop skills that will aid them in being more resilient and better able to cope with and protect themselves from the effects of workplace adversity (Jackson et al., 2007). Healthcare professionals report stress and burnout due to challenges of clinical work, time constraints, competing demands, lack of control over work processes and scheduling, and the burnout syndrome is increasingly recognized among healthcare professionals (Bridgeman et al., 2018). The Agency for Healthcare Research and Quality estimates that burnout may affect $10 \%-70 \%$ of nurses and $30 \%-50 \%$ of physicians, nurse practitioners, and physician assistants (Bridgeman et al., 2018).

The compassion and empathy shown by healthcare, emergency, and community service professionals can prove psychically, mentally, and economically costly (Cocker \& Joss, 2016). In addition to the individual human costs, symptoms of serious stress have significant economic consequences due to sickness absence and incapacity for work, and debilitating conditions such as depression and anxiety (Drury et al., 2014). These conditions are Special description of the title, (dispensable) known to increase sickness absence, psychological injury claims, and job turnover, and negatively impact productivity (Cocker \& Joss, 2016). Therefore, there is currently an increased focus on how to maintain and improve the mental health of healthcare professionals to help them cope with the challenges they face and to maintain them in their jobs. Findings suggest that a nurse's capacity to cope is strongly linked to personal resilience and is enhanced through strong social and collegial support, infrastructure that supports the provision of quality nursing care, and positive affirmation (Drury et al., 2014). These findings support the need for management to develop appropriate interventions to build resilience in nurses.

When aiming to improve mental health, Applied Positive Psychology, mindfulness-based stress reduction (MBSR), and the use of nature are three approaches known to have a positive effect upon human welfare and mental health, thereby strengthening healthcare workers' resilience (Donaldson et al., 2019; Kiken et al., 2017; Barton \& Pretty, 2010). All three areas build on what is already working for individuals and focus on enhancing human thriving.

Positive psychology has become an important field of research when focusing on what makes people thrive and how best to improve the work environment 
(Donaldson et al., 2019; Tugade \& Fredrickson, 2004; Seligman, 2002; Seligman et al., 2005). Positive psychology aims to focus on human welfare and how humans flourish. The concept of PERMA includes the elements of Positivity, Engagement, Relations, Meaning and Achievement and is by Seligman described as basic for human thriving. By focusing on these five elements and targeting exercises and training on the ability to enhance these areas it is possible to improve human thrive (Seligman, 2018).

Positive Psychology interventions (PPI) aim to increase resilience and positivity among participants. In the last years, a lot of PPIs have been conducted in order to improve work engagement and reduce stress among the employees (Donaldson et al., 2019). The concept of Positive Activities Interventions (PIA) which is described as involving simple self-administrated cognitive and behavioural strategies that, can increase subjective well-being by promoting positive feelings, thoughts, and behaviours, has in randomised controlled interventions shown increased well-being (Layous \& Lyubomirsky, 2014). Some of the activities which conduct well-being are writing letters of gratitude (Boehm et al., 2011), the act of kindness, counting one's blessings, and using your signature strengths (Virtues In-Action (VIA)) in new ways (Seligman et al., 2005; Seligman, 2002; Seligman \& Csikszentmihalyi, 2014). It appears that using signature strengths is robustly related to well-being (Gander et al., 2020). A review of the literature demonstrates the impact of working with positivity and signature strength in increasing happiness and decreasing depressive symptoms (Seligman et al., 2005), and positivity is described as the core of resilience and meditating on positive feelings towards self and others (Fredrickson et al., 2008; Fredrickson, 2013; Fredrickson, 2009). Resilience describes one's ability to navigate resistance despite adverse events. Furthermore, it is also one's ability to reach out and open towards one's environment, in both a mental and physical manner. Resilience means a capacity for growth and positive adaptation when people face adversities. Having the tools and skills to work with and improve one's resilience provides people the possibility to thrive (Tugade \& Fredrickson, 2004; Masten et al., 2008), and Reivich and Shatté describe that self-efficacy is an essential component that protects against chronic stress (Reivich \& Shatté, 2002). MBSR is also a way of improving mental health. Mindfulness originates from Buddhist philosophy and religious traditions (Segal et al., 2013). It is an experience of being in the present, in a non-judgmental manner, where the mindfulnesspractitioner meets what might arise from a situation with acceptance and openness. The use of mindfulness in relation to the treatment of stress disorders, anxiety, and depression has gained great recognition, and mindfulness techniques are widely used in interventions and practices (Chiesa \& Serretti, 2009; Gilmartin et al., 2017).

The third approach that has an impact on mental health is via nature, which is used as an agent to improve mental health. Evidence shows that exercising in nature leads to both short term and long-term positive outcomes on the state of one's mental health (Barton \& Pretty, 2010) and Berto describes that exposure to 
natural environments protects people against the impact of environmental stressors and offers physiological, emotional and attention restoration more so than urban environments (Berto, 2014).

The aim of this study was to examine whether it was possible to improve mental health and increase the well-being of healthcare professionals through a model of teaching and training in positive psychology, a brief version of MBSR, and practice in nature.

\section{Methods}

An intervention study where the effect of the intervention was assessed using interviews and questionnaire surveys.

\subsection{Participants}

The participants were nurses and secretaries employed at the Department of Anaesthesiology and Intensive Care at a regional hospital in Denmark.

\subsection{Intervention Model}

The intervention model consisted of a course with a total of four days ( 8 hours each day) with training in applied and theoretical aspects of positive psychology and MBSR, focusing on making the concepts applicable and operational. The training and exercises shifted between elements using Positive Psychology, Mindfulness, and the effect of nature. Both physical and mental skills training aimed to give the participants several tools they could pick and choose among and use in their daily life according to what made sense for each one. Approximately $55 \%$ of the intervention time was used on positive psychology and $45 \%$ of the time on MBSR, with 25\% of the teaching being conducted in nature. The training was conducted with approximately four weeks between each course day and took place in a traditional classroom setting and in nature outside the hospital. The training consisted of group sessions, solitary exercises, and home assignments between the training days. The participants were invited to use the exercises at home and at work approximately 20 minutes each day between the course days.

The participants were divided into two groups, where group one was the primary intervention group and group two served first as a control group and afterwards as the secondary intervention group. All nurses and secretaries in the department were invited to participate in the course by posters and oral introduction, and among those who applied, the Nursing head of the department chose who could participate and in which group they would be, based on practical possibilities within the work schedule. The participants were not randomised. Participation was voluntary and proceeded during work hours. The course leader (first author)-had a master's degree in positive psychology and was employed as a part-time nurse and part-time researcher in the department.

Details of the training: 


\section{Day 1}

Positive psychology in general, including PERMA (Positivity, Engagement, Relations, Meaning and Achievement);

Letter of gratitude;

Introduction to MBSR and training mental gearshift;

Meditation in the forest;

Breathing meditation and body-scan.

Day 2

PERMA again;

Finding your signature strength and strength spotting;

New perspective on stress;

Creative writing;

Meditation on sounds, walking meditation in the forest, and body-scan.

Day 3

Resilience and resistance;

Challenge the difficulties;

Meditation on a difficulty, breathing, and body-scan;

Meditation in the forest.

\section{Day 4}

Resume from training 1 - 3;

Reflection on my new skills and highlights from training 1 - 3;

How will I implement my new skills?

Meditation plan for how and when?

Meditation in the forest;

Meditation body-scan.

\subsection{Effect Assessment Interviews}

Semi-structured individual interviews were conducted with all participants within two weeks of completion of the intervention and again three months after completion. Additionally, charge nurses from the departments having participants in the study participated in a focus group interview three months after completion of the course. The interview guides were developed via a pilot project in 2016 and the first author (JSH) conducted all the interviews. Interviews were digitally recorded and afterwards transcribed.

\section{Main questions for participants}

What were the most important issues you learned from the course?

Why do you highlight these issues?

What did it mean to you?

Did this result in any changes for you?

And if can you elaborate on these changes?

How often do you use something from the course?

What did you mostly use from the course?

What impact have this had on you daily life and work? 
Did you use the $\mathrm{CD}$ and Mindfulness-guides from Youtube during the course?

Do you still use the CD, Youtube, and Workbook?

Is there something you would have liked more or less of during the course?

\section{Main questions for the charge nurses}

What are your experiences of the effects of the staffs' participation?

Have you experienced changes in the participants' care for own mental and physical health?

Have some of the participants either mentioned or shown that they try to look at own or other strengths and positivity?

\subsection{Effect Assessment. Questionnaire Surveys}

Quantitative measurements were conducted using the WHO-5 (Bech et al., 2003; Topp et al., 2015), the Positivity test (Fredrickson, 2009), and the self-compassion test questionnaires (Neff, 2016; Neff, 2003). The participants completed the three questionnaires before group one began the intervention (T1), at the completion of the intervention for group one (T2), and three months after completion of the intervention for group one (T3). T3 acted as a baseline for group two, and this group additionally filled in the questionnaires at the completion of their intervention period (T4) and three months after completing the intervention (T5). The study was conducted from September 2017 to January 2019, with group two beginning the course after $\mathrm{T} 3$.

\section{WHO questionnaire}

WHO-5 is a psychometric questionnaire constructed to measure the respondents' well-being over the last 14 days (Bech et al., 2003). The WHO-5 can be used for different populations and groups of the population and patients and is translated into 30 languages. The WHO- 5 consists of five questions with a possible range of 0 - 100. A high score correlates with well-being. If the score is below 50 , the person may have signs of stress or depression.

\section{Positivity ratio}

The positivity ratio is a psychometric questionnaire test developed by Barbara Fredrickson. The questionnaire detects the relationship between positive and negative emotions which the participant has noticed within the last 24 hours. It contains 20 questions and the score of the questionnaire is referred to as the positivity ratio. The score range is from 1-10. Scores indicating well-being range from 2.89 - 10. Scores below that may indicate failure to thrive (Fredrickson, 2009).

\section{Self-compassion scale}

The Self-Compassion Scale (Neff, 2016) measures self-compassion as a systemlevel balance between compassionate self-responding (kindness, common humanity, and mindfulness) and reduced uncompassionate self-responding (reduced self-judgment, isolation, and over-identification). Scores range from 1 - 5 and the average overall self-compassion scores tend to be around 3.0 as a rough guide, a score of $1-2.5$ for your overall self-compassion score indicates you are 
low in self-compassion, 2.5 - 3.5 indicates you are moderate, and 3.5 - 5.0 means you are high.

\subsection{Data Analysis}

The interview data were analyzed using content analysis with focus on manifest content (Graneheim \& Lundman, 2004) (Kleinheksel et al., 2020). The transcribed interviews were read repeatedly to get an overview of the participants' experiences. Then the data were condensed so that the main meaning of what had been said was reformulated in a few words. In the next stages, essential units of meaning were identified and derived in a balance between being open to what the informants experienced, and at the same time being guided by the study's problem and purpose. Finally, the meaning units were worked through to transform the informants' statements into relevant scientific terms. The first author was responsible for coding and results were discussed in the author group. Quantitative data were analysed in the statistical program Stata 15, using descriptive statistics with continuous, normal distributed data presented as mean and standard deviation (SD).

\section{Ethics}

All participants received oral information about the project. They were informed that participation was voluntary and that they could withdraw from the study at any time. All participants gave consent. If any of the participants via the questionnaires showed results indicating that they were in distress or low in psychological well-being and functioning, they would be advised to consult their general practitioner before participating in the course. The study was registered with the Danish Data Protection Agency (Journal number 17/30792) and all data were stored and analysed on the electronic research platform SharePoint. According to Danish law, the study did not need permission from the Regional Committees on Health Research Ethics.

\section{Results}

A total of ten nurses and two secretaries participated in group one, and ten nurses and one secretary in group two. The participants were a mean of 47 (range 34 -62) years old and had a mean of 22 (range 10 - 36) years of working experience. Of the 23 course participants, one was male. Some of the participants left the department or were absent due to long-term illness and could therefore not participate in all parts of the evaluation. In group one, 10 participants completed a full evaluation (two interviews and questionnaires at three time points). In group two, six participants completed full evaluation (two interviews and questionnaires at five time points).

\subsection{Interviews-Participants}

A total of 37 interviews were conducted: 18 after the end of the course and 19 
interviews three months later. Additionally, four charge nurses were interviewed. The length of the interviews varied from 7 minutes and 38 seconds to 19 minutes and 47 seconds with a median of 9 minutes and 41 seconds.

The participants reported that immediately following the intervention, close to half of them applied elements from the training programme daily, and the rest reported that they used what they had learned one to four times weekly. The different mindfulness exercises were used by most of the participants. By T3 and T5 (three months post-intervention), fewer of them used elements from the training programme daily, but most of the participants still used training elements one to four times weekly. It was mainly the breathing meditation that was mentioned, but the use of nature and making a mental gearshift was also cited. The participants experienced an increase in their self-acceptance, but also acceptance of others. Several noticed that they used nature in a more attentive way after the course and were more focused on sounds, colours, and smells in nature. Some of the participants mentioned that they were grateful that they had been given the opportunity to partake in the project, and most of the participants mentioned that they would have liked the training programme to continue, or they wished that there had been a sort of refresher course to facilitate the implementation of their new habits. Several reported that they through the course had got to know their colleagues more thoroughly and that they had discussed the training during worktime afterwards.

Four themes emerged from the analyses: Positivity and strengths, mental gear shift and serenity, self-compassion, and mental skills.

In the following section, the themes are presented together with citations from the interviews. Numbers after quotes describe group (1 or 2), time point for interviews (T2 - 5), and reference number of participants (1 - 12). T2 and T4, respectively refer to interviews right after the intervention ended, and T3 and T5 to three months after the intervention ended.

\section{Positivity and strengths}

The participants expressed that they focused more on the positive things at work and at home. Several applied some of the positivity exercises together with other people, for example, colleagues, which gave them a sense of joy. They also experienced that they had become more energised by focussing on positivity. The participants expressed that the training programme gave them the opportunity to learn new aspects of negative emotions and their role in life. They reported having an increased awareness of their own and others' strengths, and the application of strengths was mentioned as a tool in relation to the new colleagues' and the nurse-students' education in the ward.

"The three positive things exercise provides a good ending to a day-it also gives you a good start on the next day $(1, \mathrm{~T} 2,1) . "$

"I use the three god-things-exercise with my youngest son and it gives me a feeling of tenderness and caring $(1, \mathrm{~T} 2,1)$.”

"The most important elements were the exercises with values in action (VIA), 
I have become more aware of my strengths $(2, \mathrm{~T} 4,6) . ”$

"I think the most important thing is that you always have a possibility to turn to the positive angel, even though you stand in a black hole $(1, \mathrm{~T} 2,3)$."

"I have become more positive in my view on life in general." "I have been more aware of what I am good at $(1, \mathrm{~T} 2,9)$.”

\section{Mental gear shift and serenity}

Many of the participants experienced that by using applied mindfulness they found peace even in high-pressure situations. They also described that they had become more conscious of their own influence on the present situation. In particular, the breathing exercises were mentioned in relation to that.

"I'll just take a minute to myself-then I'm ready to be more positive and constructive $(1, \mathrm{~T} 2,3) . ”$

"I'm taking a breath instead of 'flying up towards the lamp', which I used to do $(1, \mathrm{~T} 2,4)$."

"The high-pressure situations will always be there, but now I am more aware of the fact that at some point they cease again $(1, \mathrm{~T} 2,4) . "$

"It is like you are getting a reset when you have used the mindfulness exercises $(1, \mathrm{~T} 2,10) . ”$

\section{Self-compassion}

The participants became more attentive towards meeting themselves with self-compassion, which means that they experienced a higher level of selfacceptance, were less self-criticising, and were aware of using mindfulness when it would be helpful. Several participants reported having an increased acceptance and tolerance of how things were in the present, and in relation to other people. Others reported that they were better at drawing a line, but also better at sensing their own boundaries.

"I am more aware that the things that frustrate me should not be allowed to take such a large place in my day $(1, \mathrm{~T} 2,1) . "$

"When I do not understand things, I try to be more open and curious towards them $(2, \mathrm{~T} 4,5)$."

\section{Mental skills}

The participants described that they had received tools and techniques to face problems and challenges in a new way. They also described that they had learned several ways to understand colleagues who expressed negative emotions. Operational mindfulness was used, which means that the participants experienced an increased awareness of one task at a time, and thereby taking better care of their own needs in relation to stress management.

"I use it a little every day (things from the course) $(1, \mathrm{~T} 2,1)$.

"In nature, I do not use headphones anymore, it is easier for me to be in nature-I like to hear it (nature) $(1, \mathrm{~T} 2,4)$."

"I was positively surprised about what I got with me from the course (1, T2, 1)."

"I have become more aware of my own reactions $(1, \mathrm{~T} 2,10) . "$ 
A couple of the participants reported having difficulties regarding meditation, and they did not feel it was a method they could apply. Others had experiences with meditation prior to the study and experienced a revitalisation of those prior experiences. At the interviews conducted three months post-intervention, several participants expressed that they experienced a fade in the use of elements from the training programme compared to during the time of the course and immediately after.

\subsection{Interview Charge Nurses}

Additionally, charge nurses participated in the focus group interview. The charge nurses experienced that the participants had been very absorbed by the course while it was taking place. However, they also experienced that the participants' activity and focus on the course content faded with time after completion of the course.

Some of the participants reported to their leader that they had used some of the tools when they had some difficulties however they did not specific report which tools. They were using the tools both in their private life and at work.

The charge nurses found it difficult to report if any of the participants had new skills in order to show self-compassion, though some reported that they act had noticed this. Some of the leaders had heard the participants talk about positivity and the "three good things exercise". The charge nurses would have liked to have received more information about and some skills in the contents of the course so that they could have supported the process for the participants.

\subsection{Questionnaires}

The response rate for the questionnaires was $100 \%(\mathrm{n}=12+11)$ at $\mathrm{T} 1,82 \%(\mathrm{n}=$ $12+9)$ at $\mathrm{T} 2,87 \%(\mathrm{n}=10+10)$ at $\mathrm{T} 3,63 \%(\mathrm{n}=7)$ at $\mathrm{T} 4$, and $82 \%(\mathrm{n}=9)$ at T5.

When looking at WHO-5, the two groups had similar levels at T1. Group one had increased scores at T2 but returned to a bit below baseline value at T3. The differences between groups one and two were mainly due to group two experiencing a drop in WHO-5 level during the control period. Increased scores for the positivity ratio were also found at $\mathrm{T} 2$ for group one, and most of the increase was maintained at T3. The score levels varied in the control group. A slight increase in self-compassion scores was found at T2 and T3 for group one. Similar levels were found in the control group (Table 1).

When looking at group two, the participants maintained a small increase in WHO-5 scores from $\mathrm{T} 4$ to $\mathrm{T} 5$, had no increase in positivity ratio, and had similar changes as in group one for self-compassion scores (Table 2). When looking at all participants, an increase in WHO-5 scores was found when the course was finished, but the difference from the baseline level was very small three months after the course ended. The increases after completion of the course and three months after were more stable for the Positivity ratio and self-compassion scores (Table 2). 
Table 1. Measurements of changes in WHO-5, positivity ratio and self-compassion test within the primary intervention group and compared to the control group.

\begin{tabular}{|c|c|c|c|c|}
\hline & \multicolumn{2}{|c|}{ Group one $^{1}$} & \multicolumn{2}{|c|}{ Group two ${ }^{2}$} \\
\hline & \multicolumn{2}{|c|}{$\mathrm{n}=10^{3}$} & \multicolumn{2}{|c|}{$\mathrm{n}=6^{3}$} \\
\hline & mean & sd & mean & sd \\
\hline \multicolumn{5}{|l|}{ WHO-5 } \\
\hline $\mathrm{T} 1^{4}$ & 69.2 & 15.3 & 69.3 & 8.3 \\
\hline $\mathrm{T} 2^{4}$ & 78.0 & 9.8 & 62.0 & 9.7 \\
\hline $\mathrm{T}^{4}$ & 67.6 & 13.4 & 58.7 & 13.8 \\
\hline difference $\mathrm{T} 2-\mathrm{T} 1$ & 8.8 & 18.3 & -7.3 & 13.4 \\
\hline difference T3-T1 & -1.6 & 23.6 & -10.7 & 12.6 \\
\hline \multicolumn{5}{|l|}{ Positivity Ratio } \\
\hline $\mathrm{T} 1$ & 3.53 & 2.67 & 2.63 & 1.28 \\
\hline $\mathrm{T} 2$ & 5.85 & 3.47 & 4.24 & 3.71 \\
\hline $\mathrm{T} 3$ & 5.48 & 3.4 & 3.51 & 2.74 \\
\hline difference $\mathrm{T} 2-\mathrm{T} 1$ & 2.32 & 5.20 & 1.61 & 4.14 \\
\hline difference T3-T1 & 1.95 & 3.25 & 0.88 & 2.94 \\
\hline \multicolumn{5}{|l|}{ Self-compassion } \\
\hline $\mathrm{T} 1$ & 3.12 & 0.63 & 3.24 & 0.22 \\
\hline $\mathrm{T} 2$ & 3.45 & 0.43 & 3.27 & 0.43 \\
\hline $\mathrm{T} 3$ & 3.44 & 0.48 & 3.10 & 0.54 \\
\hline difference $\mathrm{T} 2-\mathrm{T} 1$ & 0.33 & 0.33 & 0.03 & 0.33 \\
\hline difference T3-T1 & 0.32 & 0.33 & -0.14 & 0.46 \\
\hline
\end{tabular}

${ }^{1}$ Primary intervention group; ${ }^{2}$ Control group/secondary intervention group; ${ }^{3} \mathrm{Only}$ included responses from participants that responded at all three time-points; ${ }^{4} \mathrm{~T} 1$ : Baseline. Group one; T2: Completion of the intervention for group one; T3: Three months after completion of the intervention for group one.

Table 2. Measurements of changes in WHO-5, Positivity test, and Self-compassion test. Secondary intervention group and all participants.

\begin{tabular}{|c|c|c|c|c|c|}
\hline \multicolumn{4}{|c|}{ Group two } & \multicolumn{2}{|c|}{ All participants } \\
\hline & \multicolumn{2}{|c|}{$\mathrm{n}=6^{1}$} & & \multicolumn{2}{|c|}{$\mathrm{n}=16^{1}$} \\
\hline & mean & $\mathrm{sd}$ & & mean & sd \\
\hline \multicolumn{6}{|l|}{ WHO-5 } \\
\hline $\mathrm{T} 3^{2}$ & 58.7 & 13.8 & $\mathrm{Ta}^{3}$ & 65.3 & 15.2 \\
\hline $\mathrm{T} 4^{2}$ & 65.3 & 13.8 & $\mathrm{~Tb}^{3}$ & 73.3 & 12.7 \\
\hline $\mathrm{T} 5^{2}$ & 64.7 & 9.3 & $\mathrm{Tc}^{3}$ & 66.5 & 11.8 \\
\hline difference T4-T3 & 6.7 & 16.1 & difference $\mathrm{Tb}$ - $\mathrm{Ta}$ & 8.0 & 17.6 \\
\hline difference T5-T3 & 6.0 & 13.1 & difference Tc-Ta & 1.3 & 20.1 \\
\hline \multicolumn{6}{|l|}{ Positivity Ratio } \\
\hline T3 & 3.51 & 2.74 & $\mathrm{Ta}$ & 3.52 & 2.6 \\
\hline
\end{tabular}


Continued

\begin{tabular}{cccccc}
\hline T4 & 3.59 & 3.35 & Tb & 5.00 & 3.49 \\
T5 & 3.48 & 2.81 & Tc & 4.73 & 3.34 \\
difference T4-T3 & 0.09 & 4.27 & difference Tb-Ta & 1.48 & 4.86 \\
difference T5-T3 & -0.03 & 4.17 & difference Tc-Ta & 1.21 & 3.62 \\
Self-compassion & & & & & \\
T3 & 3.10 & 0.54 & Ta & 3.11 & 0.58 \\
T4 & 3.40 & 0.30 & Tb & 3.43 & 0.38 \\
T5 & 3.56 & 0.37 & Tc & 3.48 & 0.43 \\
difference T4-T3 & 0.30 & 0.39 & difference Tb-Ta & 0.32 & 0.34 \\
difference T5-T3 & 0.46 & 0.42 & difference Tc-Ta & 0.37 & 0.36 \\
\hline
\end{tabular}

${ }^{1}$ Only included responses from participants that responded at all time points; ${ }^{2} \mathrm{~T} 3$ : Baseline. Group two. T4: Completion of the intervention. Group two; T5: Three months after completion of the intervention. Group two. ${ }^{3}$ Ta: Baseline. All participants. Tb: Completion of the intervention. All participants; Tc: Three months after completion of the intervention. All participants.

\section{Discussion}

Based on interviews, the participants found that training in positive psychology, MBRS, and practice in nature improved their mental health and increased wellbeing. Most of the participants were using something from the intervention model one to four times a week and they had received some skills in the areas of positivity and strengths, mental gear shift and serenity, self-compassion, use of MBSR, and positive psychology. Small increases were found when looking at the objective measures WHO-5, Positivity ratio and Self-compassion ratio.

As with the results in this study, Barbara Fredrickson et al. found that working with positive emotions and meditation increased the participants' positivity during the intervention. They also found that the effect lasted up to six months (Fredrickson et al., 2008). Another study reported that the participants gained new skills in workplace adversity and increased resilience by engaging in training with personal resilience characteristics such as positive, supportive relationships and networks, self-reflection, and self-care (McDonald et al., 2012).

The current study has described a model for how to teach knowledge and train skills from theories about positive psychology, mindfulness and the use of nature. The teaching and training influenced the participants to varying degrees. The participants reported that they had received tools and techniques to face problems and challenges in a new way, and they expressed that they focused more on the positive things after the course. They also described that they had learned several ways to understand colleagues who expressed negative emotions. This corresponds with the broaden-and-build theory, which posits that "experiences of positive emotions broaden peoples' momentary thought-action repertoires, which in turn serves to build their enduring personal resources, ranging from physical and intellectual resources to social and psychological resources" (Fredrickson, 2001). 
When looking at the objective measures, the WHO-levels in the current study were substantially higher than 50 , which is the level on a scale from 0 to 100 for score indicating risk of depression (Topp et al., 2015). Overall, in 2016 22\% of people in the EU were at risk of depression according to this measure (Ahrendt et al., 2017). Even so, the intervention provided an increase in well-being, although the level decreased to the baseline level at three months.

A positivity ratio ranging from 2.89 - 10 indicates well-being based on the balance between positive and negative emotions which the participant has noticed within the last 24 hours; scores below that may indicate failure to thrive (Frederickson et al., 2008). In the current study, all scores except T1 for the control group were within the well-being range, albeit some at the low end of the range. Large standard deviation showed that there were large variations within the groups, indicating that even though the mean level was fine, individual participants may not be thriving. The positivity scale monitors the personal experience of positive and negative emotions within the last 24 hours and is considered as a snapshot. If measured every evening during a period of, for example, two to three weeks, the tendencies would be clearer (Fredrickson, 2009). It is reported that people can increase their happiness by using simple intentional positive activities (Lubormirsky \& Layous, 2013).

Almost all the measured levels of self-compassion were within the moderate level range. This means that the participants had the resources to be warm and understanding towards themselves when they suffered, failed, or felt inadequate, rather than ignoring their pain or criticising themselves (Neff, 2003).

MBSR interventions often use educational courses with 2.5 hours a week for 8 weeks plus a 7-hour retreat comprising 27 hours in total, and they do not include the applied positive psychology training (Segal et al., 2013). The intervention in the current study used 8 hours of training in applied positive psychology and mindfulness every four weeks four times, comprising 32 hours in all. A briefer version of MBSR is described as a promising way to provide mindfulness training to nurses (Ghawadra et al., 2019), and it is reported that it has an impact on the motivation of the partakers' wishes to make healthy changes when using positive emotions (Cappellen et al., 2019). Positive changes in levels of stress and anxiety have also been reported in several studies when using brief training in mindfulness (Gilmartin et al., 2017). The review also describes that it is necessary to select from several mindfulness interventions and offer them in various formats to enhance provider engagement (Gilmartin et al., 2017). This is in accordance with the current study, as it differed in the group of participants depending on what they preferred to use. Therefore, there may be a synergistic effect combining positive psychology, mindfulness, and nature combined in an intervention, but further investigations must be conducted to confirm this.

Interventions aimed at improving mental health and increasing the well-being of healthcare professionals are important due to the fact that nurses have a high level of psychological stress (Riet et al., 2018). Likewise, nurses working in highrisk areas are vulnerable to burnout, and burnout scores among nurses are sig- 
nificantly higher than the rest of the society (Aiken et al., 2002). Resilience and robustness help the nurses to cope with daily demands at work, such as new work tasks, education, busyness, and lack of breaks. Providing a safe and healthy work environment is primarily the responsibility of the management and therefore this kind of intervention should always be an option for the employee, not mandatory. The employee should want to obtain the knowledge and skills coming from intrinsic motivation, as named in the theory of self-determination (SDT) where Deci and Ryan make it explicit that the learning should contain interest, enjoyment, and satisfaction in order to get the best outcome from the learning process (Ryan \& Deci, 2020). Thus, by giving employees skills and training, so that they can face problems that need to be solved by using positive psychology and a focus on increased positivity to increase resilience and wellbeing, help them to find new solutions to old problems and challenges (Fredrickson, 2009). Furthermore, using MBSR makes it possible to enhance selfefficacy by decreasing stress and anxiety. Therefore, this gives the employees more surplus (Bandura, 2014).

When using positive psychology theories and interventions, it is important to consider that there is a difference between "pursuing happiness and achieving it through meaningful pursuits (Bandura, 2014)." Thus, the goal is not to chase happiness, but to find the activities that enhance positivity to be aware of personal strengths and of how to cultivate these and use them in new ways. This gives the opportunity for well-being (Fredrickson, 2009). One criticism of positive psychology is that it paints the world as better than it is and hides problems, and therefore if that is the angle then it will not provide greater well-being to the employees. The focus should always be on activities that provide the possibility to enhance positivity, while not neglecting the negative emotions. A realization that what matters is the balance between positive and negative emotions is of great importance.

The strengths of the study include the use of mixed methods and having a control group. Limitations of the study include it being a single centre study with a small group of participants, the large drop-out rate of participants filling in all questionnaires, non-randomisation in group allocation, and the fact that the project leader and course teacher also conducted the interviews and had an inside position as a colleague of the participants. This may have induced the participants to assess the course and its effects in a more positive way than otherwise may have been the case.

\section{Conclusion}

Applying positive psychology and mindfulness may increase the positivity and mental robustness among healthcare professionals, and this study has described a model to teach knowledge and train practice skills from theories related to positive psychology and mindfulness. Further research is necessary to confirm a significant increase in robustness and reduction in strain symptoms. 


\section{Relevance for Clinical Practice/Perspective}

The aim of positive psychology is to help people to thrive and flourish by focusing on the activities that foster positive emotions, the attention and use of personal strengths, and not chasing positivity for the sake of the emotion. The opportunity to work with these areas and learn from one's own and others' experiences during the intervention, and hopefully afterwards as well, provides healthcare professionals with tools and skills in daily life to face the obstacles and traumas that are a part of being human. It is important to assist healthcare professionals to develop skills that will aid them in being more resilient and better able to cope with and protect themselves from the effects of workplace adversity. Healthcare professionals face numerous challenges in their daily work and these challenges entail a need for a certain amount of mental robustness to prevent strain symptoms and stress. Therefore, it makes sense to train in areas that support well-being and resilience for the benefit of both healthcare professionals and patients.

\section{Data Availability}

The datasets generated during and/or analysed during the current study are available from the corresponding author on reasonable request.

\section{Acknowledgements}

The authors thank participants and department management of Anesthesia and Intensive Care, Lillebaelt Hospital, Kolding, University Hospital of Southern Denmark, for giving the opportunity to run this study and the research for this article.

\section{Funding Source}

The study was supported by the Department of Anesthesia and Intensive Care, Lillebaelt Hospital, Kolding, University Hospital of Southern Denmark, Sygehusvej 24, DK-6000 Kolding

The funding department had no influence on the study or the paper.

\section{Ethical Approval}

According to Danish law the study did not need approval from the Regional Ethics Committee.

The study was registered with the Danish Data Protection Agency (Journal number 17/30792).

\section{Conflicts of Interest}

The authors received no specific funding for this work and declare no conflict of interest.

\section{References}

Ahrendt, D., Anderson, R., Dubois, H., Jungblut, J. -M., Leončikas, T., Pöntinen, L., \& 
Sando, E. (2017). European Quality of Life Survey 2016: Quality of Life, Quality of Public Services, and Quality of Society. Publications Office of the European Union, Luxembourg.

https://www.eurofound.europa.eu/sites/default/files/ef_publication/field_ef_document/ ef1733en.pdf

Aiken, L., Clarke, S. P., Sloane, D. M., Sochalski, J., \& Silber, J. H. (2002). Hospital Staffing and Patient Mortality, Nurse Burnout, and Job Dissatisfaction. Journal of American Medical Association, 288, 1987-1993. https://doi.org/10.1001/jama.288.16.1987

Bandura, A. (2014). A Social Cognitive Perspective on Positive Psychology. International Journal of Social Psychology, 26, 7-20. https://doi.org/10.1174/021347411794078444

Barton, J., \& Pretty, J. (2010). What Is the Best Dose of Nature and Green Exercise for Improving Mental Health? A Multi-Study Analysis. Environmental Science \& Technology, 11, 3947-3955. https://doi.org/10.1021/es903183r

Bech, P., Olsen, L. R., Kjoller, M., \& Rasmussen, N. K. (2003). Measuring Well-Being Rather than the Absence of Distress Symptoms: A Comparison of the SF-36 Mental Health Subscale and the WHO-Five Well-Being Scale. International Journal of Methods in Psychiatric Research, 12, 85-91. https://doi.org/10.1002/mpr.145

Berto, R. (2014). The Role of Nature in Coping with Psycho-Physiological Stress: A Literature Review on Restorativeness. Behavioral Science, 4, 394-409. https://doi.org/10.3390/bs4040394

Boehm, J. K., Lyubomirsky, S., \& Sheldon, K. M. (2011). A Longitudinal Experimental Study Comparing the Effectiveness of Happiness-Enhancing Strategies in Anglo Americans and Asian Americans. Cognition \& Emotion, 25, 1263-1272. https://doi.org/10.1080/02699931.2010.541227

Bridgeman, P. J., Bridgeman, M. B., \& Barone, J. (2018). Burnout Syndrome among Healthcare Professionals. American Journal of Health-System Pharmacy, 75, 147-152. https://doi.org/10.2146/ajhp170460

Cappellen, P. V., Catalino, L. I., \& Fredrickson, B. L. (2019). A New Micro-Intervention to Increase the Enjoyment and Continued Practice of Meditation. Emotion, 20, 1332-1343. https://doi.apa.org/doi/10.1037/emo0000684

Chiesa, A., \& Serretti, A. (2009). Mindfulness-Based Stress Reduction for Stress Management in Healthy People: A Review and Meta-Analysis. The Journal of Alternative and Complementary Medicine, 15, 593-600. https://doi.org/10.1089/acm.2008.0495

Cocker, F., \& Joss, N. (2016). Compassion Fatigue among Healthcare, Emergency and Community Service Workers: A Systematic Review. International Journal of Environmental Research and Public Health, 13, Article No. 618. https://doi.org/10.3390/ijerph13060618

Donaldson, S. I., Lee, J. Y., \& Donaldson, S. I. (2019). Evaluating Positive Psychology interventions at Work: A Systematic Review and Meta-Analysis. International Journal of Applied Positive Psychology, 4, 113-134. https://doi.org/10.1007/s41042-019-00021-8

Drury, V., Craigie, M., Francis, K., Aoun, S., \& Hegney, D. G. (2014). Compassion Satisfaction, Compassion Fatigue, Anxiety, Depression and Stress in Registered Nurses in Australia: Phase 2 Results. Journal of Nursing Management, 22, 519-531. https://doi.org/10.1111/jonm.12168

Fredrickson, B. L. (2001). The Role of Positive Emotions in Positive Psychology: The Broard and Build Theory of Positive Emotions. American Psychologist, 56, 218-226. https://doi.apa.org/doi/10.1037/0003-066X.56.3.218

Fredrickson, B. L. (2009). Positivity. New York, NY: Crown Publishers.

Fredrickson, B. L. (2013). Love 2.0. How Our Supreme Emotion Affects Everything We Feel, Think, Do and Become. New York, NY: Hudson Street Press. 
Fredrickson, B. L., Cohn, M. A., Coffey, K. A., Pek, J., \& Finkel, S. M. (2008). Open Hearts Build Lives: Positive Emotions, Induced Through. Journal of Personality and Social Psychology, 95, 1045-1062. https://doi.apa.org/doi/10.1037/a0013262

Gander, G., Hofmann, J., Proyer, R. T., \& Ruch, W. (2020). Character StrengthsStability, Change, and Relationships with Well-Being Changes. Applied Research in Quality of Life, 15, 349-367. https://doi.org/10.1007/s11482-018-9690-4

Ghawadra, S. F., Abdullah, K. L., Choo, W. Y., \& Phang, C. K. (2019). Mindfulness-Based Stress Reduction for Psychological Distress among Nurses: A Systematic Review. Journal of Clinical Nursing, 28, 377-3758. https://doi.org/10.1111/jocn.14987

Gilmartin, H., Goyal, A., Hamati, M. C., Mann, J., Saint, S., \& Chopra, V. (2017). Brief Mindfulness Practices for Healthcare-A Systematic Review. American Journal of Medicine, 130, 1219.E1-1219.E17. https://doi.org/10.1016/j.amjmed.2017.05.041

Graneheim, U. H., \& Lundman, B. (2004). Qualitative Content Analysis in Nursing Research: Concepts, Procedures, and Measures to Achieve Trustworthiness. Nurse Education Today, 24, 105-112. https://doi.org/10.1016/j.nedt.2003.10.001

Jackson, D., Firtko, A., \& Edenborough, M. (2007). Personal Resilience as a Strategy for Surviving and Thriving in the Face of. Journal of Advanced Nursing, 60, 1-9. https://doi.org/10.1111/j.1365-2648.2007.04412.x

Kiken, L. G., Lundberg, K. B., \& Fredrickson, B. L. (2017). Being Present and Enjoying It: Dispositional Mindfulness and Savoring the Moment Are Distinct, Interactive Predictors of Positive Emotions and Psychological Health. Mindfulness, 8, 1280-1290. https://doi.org/10.1007/s12671-017-0704-3

Kleinheksel, A. J., Rockich-Winston, N., Tawfik, H., \& Wyatt, T. R. (2020). Demystifying Content Analysis. American Journal of Pharmaceutical Education, 84, 7113. https://doi.org/10.5688/ajpe7113

Layous, K., \& Lyubomirsky, S. (2014). The How, Why, What, When, and Who of Happiness: Mechanisms Underlying the Success of Positive Activity Interventions. In J. Gruber, \& J. T. Moskowitz (Ed.), Positive Emotion (pp. 473-495). Oxford: Oxford University Press. https://doi.org/10.1093/acprof:oso/9780199926725.003.0025

Lubormirsky, S., \& Layous, K. (2013). How Do Simple Positive Activities Increase Well-Being? Current Directions in Psychological Science, 22, 57-62. https://doi.org/10.1177\%2F0963721412469809

Masten, A. S., Best, A. S., \& Garmezy, N. (2008). Resilience and development: Contributions from the Study of Children Who Overcome Adversity. Developement and psychopathology, 2, 425-444. https://doi.org/10.1017/S0954579400005812

McAlister, M., \& Lowe, J. B. (2011). Preparing for Practice. In M. McAlister, \& J. B. Lowe (Eds.), The Resilient Nurse (pp. 17). New York, NY: Springer Publishing Company.

McDonald, G., Jackson, D., Wilkes, L., \& Vickers, M. H. (2012). A Work-Based Educational Intervention to Support the Development of Personal. Nurse Education Today, 32, 378-384. https://doi.org/10.1016/j.nedt.2011.04.012

Neff, K. D. (2003). The Development and Validation of a Scale to Measure SelfCompassion. Self and Identity, 2, 223-250. https://doi.org/10.1080/15298860309027

Neff, K. D. (2016). The Self-Compassion Scale Is a Valid and Theoretically Coherent Measure of Self Compassion. Mindfulness, 7, 1009. https://doi.org/10.1007/s12671-016-0560-6

Reivich, K., \& Shatté, A. (2002). The Resilience Factor (1st ed.). New York, NY: Three Rivers Press. 
Riet, P. V., Levett-Jones, T., \& Aqino-Russel, C. (2018). The Effectiveness of Mindfulness Meditation for Nurses and Nursing Students: An Integrated Literature Review. Nurse Education Today, 65, 201-211. https://doi.org/10.1016/j.nedt.2018.03.018

Ryan, R. M., \& Deci, E. L. (2020). Intrinsic and Extrinsic Motivation from a SelfDetermination Theory Perspective: Definitions, Theory, Practices, and Future Directions. Contemporary Educational Psychology, 61, Article ID: 101860. https://doi.org/10.1016/j.cedpsych.2020.101860

Segal, Z. V., Williams, M. G., \& Teasdale, J. D. (2013). Mindfulness-Based Cognitive Therapy for Depression (2nd ed.). New York, NY: Guildford Press.

Seligman, M. (2002). Positive Psychology, Positive Prevention and Positive Therapy. In C. R. Snyder, \& S. J. Lopez (Eds.), Handbook of Positive Psychology (pp. 3-9). Cary, NC: Oxford University Press US.

Seligman, M. (2018). PERMA and the Building Blocks of Well-Being. The Journal of Positive Psychology, 13, 333-335. https://doi.org/10.1080/17439760.2018.1437466

Seligman, M., \& Csikszentmihalyi, M. (2014). Positive Psychology: An Introduction. In M. Csikszentmihalyi (Ed.), Flow and the Foundations of Positive Psychology (pp. 279-298). Dordrecht: Springer. https://doi.org/10.1007/978-94-017-9088-8_18

Seligman, M., Steen, T. A., Park, N., \& Peterson, C. (2005). Positive Psychology Progress. American Psychologist, 60, 410-421.

https://doi.apa.org/doi/10.1037/0003-066X.60.5.410

Topp, C. W., Østergaard, S. D., Søndergaard, S., \& Bech, P. (2015). The WHO-5 WellBeing Index. Psychotherapy and Psychosomatics, 84, 167-176.

https://doi.org/10.1159/000376585

Tugade, M. M., \& Fredrickson, B. L. (2004). Resilient Individuals Use Positive Emotions to Bounce Back From. Journal of Personality and Social Psychology, 86, 320-333.

https://doi.apa.org/doi/10.1037/0022-3514.86.2.320 